\title{
The Bystander in Commercial Life: Obliged by Beneficence or Rescue?
}

\author{
Wim Dubbink ${ }^{1,2}$
}

Received: 1 November 2014/ Accepted: 3 March 2016/Published online: 30 March 2016

(c) The Author(s) 2016. This article is published with open access at Springerlink.com

\begin{abstract}
Liberalist thinking argues that moral agents have a right (or duty) to pursue an ordinary life. It also insists that moral agent can be bystanders. A bystander is involved with morally bad states of affairs in the sense that they are bound by moral duty, but for a non-blameworthy reason. A common view on the morality of commercial life argues that commercial agents cannot and ought not to assume the status of bystander, when confronted with child labor, pollution, or other overwhelmingly big morally bad states of affairs (oMBS). According to the common view, the agent will get overdemanded. In this paper, the overdemandingness charge is interpreted as a criticism of the liberalist position. According to this charge, bystander status must be given up in the market because otherwise the right (or duty) to pursue a personal life is crushed. In this paper, we demonstrate that the overdemandingness charge fails. It does not make sense if bystander status is grounded in the duty of beneficence. It would make sense if the status were grounded in the duty of rescue but that duty does not apply in relation to oMBS. The condition of 'subjective urgency' is not fulfilled. Hence, liberalist thinking can withstand the charge of overdemandingness and commercial agents cannot assume a right never to acknowledge bystander status (on account of the overdemandingness argument).
\end{abstract}

Wim Dubbink

w.dubbink@uvt.nl

1 Department of Philosophy, School of Humanities (TSH), Tilburg University, Tilburg, The Netherlands

2 Robert van Guliklaan 22, 7207 CB Zutphen, The Netherlands
Keywords Bystander - Beneficence $\cdot$ Rescue $\cdot$ Morally bad states of affairs - Overdemandingness - Personal morality $\cdot$ Subjective urgency

\section{Introduction}

Moral agents are often confronted with "morally bad states of affairs' (MBS). A MBS can formally be defined as a situation that is objectionable, reprehensible, or even intolerable from the moral point of view. MBS differ as widely as the refugee problem differs from the victim of a robbery. When a moral agent is a bystander to a MBS, what is the basis for the actions they may have to perform on account of duty: rescue or beneficence? In this paper, it is argued that a proper understanding of the ground, helps avoiding the charge that commercial agents cannot be considered bystanders because that would create an overdemandingness problem.

The concept 'bystander' is crucial to this paper. We reserve the term for a moral agent who is-or becomesinvolved in a MBS in the sense that they are obliged by moral duty but for a non-blameworthy reason (Dunfee 2006; Hill 2012; Radzik forthcoming). A standard example of bystander involvement in the literature is when a person happens to walk past a pond in which a person is drowning (Kamm 2000, p. 656). In that urgent situation the nonblameworthy, circumstantial fact of proximity to the potential drowning transforms the non-involved passerby into a bystander who is involved by duty.

The concept bystander-as we use it—only makes sense when particular assumptions about morality are made. The concept presupposes that it is meaningful to distinguish between bad things we somehow 'do to others' (i.e., are to blame for) and bad things that merely 'happen to others.' 
We must be able to make a meaningful distinction between 'wrong' and '(merely) bad' (Fried 1978). This presupposition only makes sense when it is assumed that moral agents must also have concern for their own life plan; either as a right (Miller 2004; Schmidtz 2000) or as an (indirect) duty as well as a right (Kant 1797/1996). This assumption is part of many moral traditions but it is articulated in particular in the 'liberalist tradition,' as we will refer to it. This tradition-on which we focus-assumes that each moral agent has a right and a duty to pursue a normal or ordinary life (Herman 2007; Rawls 1971). In the liberalist tradition, 'wrong' defines a relationship between the MBS and an agent in terms that identify the latter as accountable and to blame. Child labor and robberies should not exist. When they do, that is wrong; meaning that at some level one or more moral agents fail because of that fact. When something is 'merely bad' the agent ought to regret it but they are not accountable or blameworthy related to its coming about. A young person dying of cancer may count as an example of the latter. Typically, we do not hold anybody to blame for a situation like that.

Yet, the concept 'bystander' also presupposes that the agent who is not blameworthy involved as regards the rise of the MBS, may (sometimes) still have duties toward others who find themselves in MBS. The way they deal with or relate to the situation may still be the cause of moral failure (Frankena 1963/1973; Kant 1797/1996, vol. VI, p. 452; Hill 2012; Herman 2007; Rawls 1971). If there were no duties in relation to how the moral agent must respond to a confrontation, they were always either blameworthy involved in MBS or mere 'outsiders.' The status of bystander and the specific problems related to that status (i.e., overdemandingness) could not even arise. (This is why we exclude the libertarian niche of liberalism from our definition of the liberalist tradition. Libertarians argue that it may be good or praiseworthy for the nonblameworthy moral agent to have moral concern in situations in which the agent is confronted with a MBS but there are never duties to acknowledge (Fried 1978; Nozick 1975).)

The concept 'bystander' further presupposes that we take the personal (or micro) perspective in reflections on moral duty. This perspective must be contrasted with the political-ethical (or macro) point of view. When we take the latter perspective, the line between 'wrong' and 'bad' is drawn between what is wrong and merely bad from the moral community point of view. What is wrong can for example be concretized in terms of things 'people owe others' (Scanlon 1998) or the idea of 'duties of Right' (Kant 1797/1996). We can thus categorize robbery as unjust, while (unwanted) loneliness is merely bad. It is also characteristic of the political-ethical perspective to conceptualize morality in terms of realizing a situation. Morality's demands are not fully redeemed as long as all agents do not have 'what is owed to them.' As long as there is something that the community must identify as 'wrong' it cannot rest.

While taking the personal perspective, the moral agent asks: how am I to relate to a situation I am confronted with, regardless of the fact whether I can solve the issue (by myself) and also regardless of the role others (communities, governments etc.) have to play? Although performing tasks is also important in this perspective, the relational aspect is paramount. From the personal perspective morality requires the agent to relate to a MBS in a certain way. Actions (doing things and performing tasks) are important but saving one's moral agency by relating to an issue in a certain way is crucial. The distinction between 'wrong' and 'merely bad' remains meaningful in this perspective but the line between the two is drawn differently. If I am confronted with a MBS while taking the personal perspective, I only have to consider my relation to its coming about as 'wrong' when my personal involvement in this process makes me blameworthy; it is 'merely bad' when I am not so involved. When I see a robbed person that I have not robbed, while I also neither have been an accomplice to the culprit nor have benefitted from the robbery, I confront a situation that is 'merely bad' to me. Yet, if it turns out that I must consider myself a bystander, I must acknowledge duties in my proper response.

What are the implications of having to assume the status of bystander? If a moral agent must consider themselves bystander, they cannot walk away indifferently anymore. Their response is bound by duty and will involve supportive action of some kind, even if that will not solve the problem (as a whole). It has been argued that in a world in which there are many and many enormous MBS moral agents will get overdemanded because of their bystander duties. Liberalist thinking is not fit for modern times, so to speak, with its insistence that agents have a right to an ordinary life and bystander duties at the same time. It must grant moral agents a moral right to reject bystander status. Otherwise, it cannot redeem its commitment to the principle that each person has a right to an ordinary life. In this paper, we investigate this claim.

We restrict the discussion on this claim to commercial life. The idea that moral agents have a right to moral indifference in relation to MBS they are non-blameworthy related to in terms of its coming about, is part and parcel of a common view on business morality. According to this view, market morality must be a 'minimum morality' (Baumol 1975; Donaldson 1989; Elfstrom 1991; Homann 1994, 2008; see also Hsieh 2004). A defining aspect of this minimum market morality (MMM) is the exclusion of all the duties of the bystander. 


\section{Kinds of Morally Bad States of Affairs}

We restrict the investigation in several ways. We limit the investigation about the claim to a special kind of MBS. It is quite usual to distinguish between problems a person could deal with (i.e., solve) on their own and problems that require cooperation. The first we refer to as (normal) MBS and the latter as collective MBS (cMBS). When a victim is robbed, a passing-by moral agent who becomes a bystander can fulfill all rescue duties by themselves. When a big bushfire threatens to burn down 25 houses, one bystander can only do so much. More bystanders are called for, and they need to cooperate, plan, and so forth in order to fulfill their bystander duties.

From the personal perspective it makes sense to distinguish between kinds of MBS in a different way, especially if overdemandingness is the issue. This is the distinction between (normal) MBS and-what we refer to as-overwhelmingly big MBS (oMBS). Whereas the distinction between MBS and cMBS relates to different properties of the MBS, the distinction between MBS and oMBS refers to the relation between the agent and the MBS. In case of an oMBS, the agent finds themselves in a situation in which they can rightfully claim that they are overwhelmed by the MBS. This claim is not just a subjective psychological feeling but a situation in which moral agents can legitimately claim to be overwhelmed. It is clear that the agent cannot deal with the situation on their own. The circumstances are even worse: in case of an oMBS anything that would mean only the tiniest bit in terms of solving the problem, immediately threatens the right to pursue an ordinary life. At the same time, the agent can rightfully claim in relation to an oMBS that anything they can do that is still in line with their right to have an ordinary life, is meaningless, if solving the problem is the only thing that counts. That is why oMBS sometimes come with the psychological feeling that one might as well do nothing. Doing something has an element of absurdity. Why bother about saving one person if the life of a million people are at risk? (This psychological feeling is mistaken exactly because it overlooks the personal perspective, but that is another matter).

Since oMBS are defined by a relation, they do not exist in the way cMBS exist: as a specific kind of problem with specific properties. As soon as a cMBS becomes big enough, it may turn into an oMBS. If a bushfire gets really big, it may overwhelm the bystander. Still, especially in relation to the discussion on the bystander in commercial life, the typical oMBS is a global problem, like child labor, structural and large-scale poverty, an epidemic disease (i.e., AIDS), the refugee problem, or the dramatic extinction of natural life. These typical oMBS have a special characteristic: they only exist in reflection, in the sense that a moral agent cannot point at these problems in real life. They can only point at a symbolic instantiation*- or a token of the problem. When a person accidently drowns in a pool, there is a sense in which we can say that the bystander can really 'see' and point at the problem in the empirical world (even if many philosophers will emphasize that this process of 'seeing' already requires interpretation of reality). This idea of pointing at 'the problem' is already more difficultand different-with medium-sized cMBS. If we want to point at 'the problem' we can point at one burning house. But if so, we are either pointing at a part of the problem or something that functions as a symbol or token for the problem as such. In the case of an exemplary oMBS, we can no longer point at a specific case as 'the problem,' not even as a part. The problem as such is only accessible through its instantiations and (some) individual cases symbolically function as instantiations. One particular picture of Aylan Kurbani (the dead 3-year-old washed ashore on the Turkish beach, September 2015) represents the refugee crisis of 2015. His tragic death is too small an event to function as 'a part' of the problem. Yet, the picture taken at the Turkish beach represents the refugee crisis as such. Exactly because of that fact, individual moral agents experience to be overwhelmed by such a problem - and have a right to that experience.

In this paper we focus on oMBS, in particular the exemplary oMBS that provoke the experience of being overwhelmed because of the way we (must) think them. The proposition we defend is that if liberalist thinking does not have an overdemandingness problem in relation to these exemplary oMBS, it does not have an overdemandingness problem at all.

The second restriction of the paper is that we will only investigate the possible ground of obligation in relation to an oMBS. We do not investigate what bystanders must do in terms of (concrete) actions. When a moral agent becomes a bystander, it is natural to think that they must do things. They must 'help,' 'rescue,' or at least must be considered to have an obligation to consider these actions. The paper does not go into the content of these actions. It is a formal exercise into the possible grounds of obligation, when a person is a bystander. Even more precise: we investigate what the bystander ought to consider the specific ground of obligation when confronted with an oMBS. We evaluate two possible duties that could serve as possible grounds of obligation: the duty of beneficence and the duty of rescue. (Please note that we must distinguish between actions that can be described as "helping" or "rescuing" and the grounds of obligation 'beneficence' and 'rescue.' Many actions can be described as 'helping' and these actions can have all manner of grounds, e.g., a paid 
plumber may be said to "help us" with a leaking tap. We are only interested in actions originating in beneficence and rescue as ground. As such the duty of beneficence may lead to actions that can be described as 'rescuing').

The need to differentiate between the two grounds often goes unrecognized. Miller (2004) uses duty of 'rescue,' duty of 'beneficence,' and even duty of 'aid' interchangeably as grounds for people to provide aid or perform rescuing activities (See also Kamm 2000; Schmidtz 2000; Soule et al. 2009). What is more, in so far as the distinction is made, there is a tendency to think that the duty of rescue is the natural-or only possible-ground of obligation for the bystander in relation to oMBS (Dunfee 2006; see also Scanlon 1998).

By contrast, we will argue that when confronted with an oMBS, the ground of obligation must be the duty of beneficence. If that duty is the ground of obligation there cannot be an overdemandingness problem. We will also argue that liberalist thinking cannot allow the duty of rescue to be the proper ground in relation to oMBS. If so, it cannot foreclose the overdemandingness problem. It fails as a normative theory. It can no longer reconcile bystander duties in relation to oMBS and moral agent' right (i.e., duty) to pursue their own life. Hence, in that case it must grant moral agents a moral right to never to acknowledge bystander duties when confronted with oMBS.

The third restriction of the paper is that we limit our investigation to the issue: if a moral agent has the status of bystander, what follows? ${ }^{1}$ Given this third restriction some worries and concerns do not apply to the paper. Some people ask themselves how a moral agent becomes a bystander. When and how do moral agents transform from an 'outsider' to a 'bystander'? What are legitimate criteria, and so forth. Given our restriction we pass by all these issues. We only need to make one formal point about the transformation process. It concerns the concept 'being well-placed.' It seems that common morality makes the status of bystander depend on a complex array of significant symbolic facts. Examples of such symbolic significant facts include (literal or symbolic) proximity to a problem, expertise, social relatedness, and an existing relationship with a victim or a perpetrator of injustice. For example: in the most obvious case of a person drowning, literal proximity to the pond transforms an agent into a bystander. The symbolic facts have in common that the bystander is somehow specially related to the MBS. Good swimmers

\footnotetext{
${ }^{1}$ Pogge (2002) has argued that people in affluent societies argue way too quickly that they are mere bystanders to MBS elsewhere on the planet. More often than we think, we actually are blameworthy involved in MBS. This paper does not necessarily conflict with this position. It merely asks: if there are some cases in which the moral agent can rightfully claim to be bystander, what follows in those situations?
}

will become bystanders, when someone is drowning, all things considered equal. By the same token, a doctor acquires the status when they are present in a movie theater while someone gets a heart attack. We refer to this condition as 'being well-placed.' We use this as a purely formal term. When an agent is well placed, morally speaking, it goes by definition that they stand out among other moral agents and this outstanding position transforms them into a bystander (all things considered equal).

As a consequence of the third restriction, we can also pass by the question whether organizations can be bystanders. People raise this issue because the moral status of the organization is disputed in today's moral discussions. This issue is especially debated in commercial life, as many market agents are organizations. We can simply relate to this discussion by saying: if organizations can be full-fledged moral agents, they can also be bystanders. If they cannot be moral agents at all, they also cannot be bystanders. If they can be moral agents of some kind, it depends on the exact way human beings think they can and have a right to impute moral duties on them. An important reason for being unconcerned about the issue is that this paper's main aim is to object to a view that states that agents on the market have a right to moral indifference, because of the overdemandingness problem. The authors who make that claim also do not make this consideration relevant to their argument. In their view, overdemandingness would also be a problem in a market without corporations. At a minimum, our argument also relates to such a world.

We proceed to explain the overdemandingness problem ("Market Morality and Overdemandingsness" section). Subsequently, we demonstrate why grounding bystander involvement in relation to oMBS on the duty of beneficence does not lead to the problem of overdemandingness ("The Duty of Beneficence and Its Structure" section). Then, we argue why the duty of rescue fails as a ground for bystander involvement in relation to oMBS ("The Duty of Rescue," "The Duty of Rescue and oMBS," "Subjective Urgency" sections). In the last section, we demonstrate why and how beneficence is not a 'weak' and therefore meaningless duty in relation to oMBS ("Beneficence as a Meaningful Duty" section).

\section{Market Morality and Overdemandingness}

In thinking about the morality of the market, a common view holds that commercial agents can never assume the status of bystander. Some argue that the nature of commercial life or the role commercial agents have to play, per definition contradicts with the idea of a bystander (Habermas 1981; Luhmann 1988; Weber 1921/1972). 
Others simply hold that the status of bystander does not exist (Nozick 1975).

A third group has a different kind of argument to reject the possibility of the status having relevance in commercial life. Acknowledging the relevance and possibility of bystander status in commercial life would lead to immoral situations and practical contradictions, (Donaldson 1989; Donaldson and Dunfee 1999; Homann 2008; U.N. 2008). Commercial agents would immediately be ruined if they were morally obliged to accept bystander status. They would be overdemanded. Commercial agents must be protected from this and hence be given a right to moral indifference. Although protagonists of the argument usually do not put it that way, the overdemandingness problem can be interpreted as a criticism of liberalist thought. The criticism points out that given modern conditions, liberalist thinking can no longer reconcile the moral agent's right (or duty) to pursue their own life with bystander duties. It must therefore accommodate to modern circumstances and give up bystander duties (in commercial life).

The key to this argument is the concept of overdemandingness. Overdemandingness arises if the moral requirements that the agent must acknowledge place the same agent in a situation in which they are no longer able to fulfill other moral duties or take care of their own legitimate concerns (See Bosma 2012; Van den Hoven 2006; also see Goodin 2009; Herman 2007). We limit the overdemandingness problem to the (exemplary) oMBS. If the overdemandingness argument makes sense at all, it must make sense in relation to oMBS. Naturally, there is an obverse to this thesis: if it can be shown that the overdemandingness problem does not make sense in relation to oMBS, it does not make sense at all.

Before we criticize the overdemandingness argument, we will formulate it as strong as possible. We do this by rebutting some of the (natural) objections, raised against the very idea. An objection that may arise against the concept is that morality cannot rule out the possibility that the demands of morality are steep. If your parents fall ill and you have to take care of them your life may be seriously uprooted for a long time (assuming that in an individualist culture these activities are considered as "uprooting your life"). Morality does not give you a break here merely because this obligation is steep. This objection misfires. It overlooks that the overdemandingness argument interprets the concept as a moral term. It refers to situations in which a moral agent has a legitimate moral right (or even a duty) to claim that too much is being demanded of them. Within the liberalist tradition this possibility must be taken into account since moral agents also have a right (or duty) to have concern for their own life. In case of (moral) overdemandingness, it is immoral and contradictory still to demand the action. A "desert island" example is when an individual's life is eaten up by a constant stream of total strangers they need to rescue, while trying to build a small house for their spouse and children.

Another objection that naturally arises is that some people will subjectively consider themselves overdemanded much sooner than others. A greedy agent may consider themself overdemanded by having to donate just a little bit of money to the worldly poor. Are these people sooner "off the hook"? Not really; the objection overlooks that overdemandingness is a moral term. It refers to a situation that a moral agent may find themselves in. The definition of the situation is based on (intersubjectively shared) rational arguments, not subjective considerations. It is the same as with killing a person out of self-defense. Situations in which an agent can claim the right to selfdefense are not based on subjective evaluations of the situation but on (shared) rational arguments determining whether an agent is in that situation. The same rebuttal applies to the closely related objection that some people feel overdemanded much quicker than others. Again, the argument does not interpret overdemandingness as a psychological condition. It refers to a moral condition moral agents may find themselves in.

It has also been objected to the concept of overdemandingness that it has paradoxical and immoral effects. It seems to stimulate agents to diminish their capacity to deal with moral problems. The sooner you can claim to be overdemanded, the sooner you are off the hook, morally speaking. The arguments mentioned above can be used against this objection also, but additional things need to be pointed out as well. The objection overlooks that overdemandingness is a moral problem that stands in need of reflection in liberalist moral community. That some of the arguments of this moral reflection will (later) be used by non-moral agents as bad excuses to get away with their behavior is saddening but beside the point. In so far as an agent is a moral agent, it is contradictory for them to use these excuses. It also needs to be added that the objection seems to look at overdemandingness as an argument to be used in 'applied ethics' or 'moral case analyses,' in which agents may be looking at reasons (or excuses) to diminish their personal involvement. The reflection on the concept of overdemandingness as pursued here, takes place at a different level of moral reasoning. It only makes sense at the reflective level at which moral agents determine what must be considered the proper set of duties that moral agents must acknowledge in life (i.e., when confronted with real cases). At that level of reflection, the liberalist conception cannot dismiss the concept of overdemandingness, given its adherence to the idea that each agent has a right (and a duty) to have concern for their own life. At this level, liberalist thinking must come up with a set of duties 
that foreclose the possibility of overdemandingness, otherwise moral agents cannot reasonably apply morality to cases.

In line with this, it may be instructive to distinguish between the formal concept and the material concept. As a formal concept, 'overdemandingness' can be interpreted as referring to the situation in which the set of (concrete) duties will by definition badger the possibility that the moral agent can have sufficient concern for their own life. From a liberalist perspective, allowing for the possibility of overdemandingness as a formal concept is necessary, given the concern it has for the right (or duty) each moral agent ought to have for their own life. Liberalist thought would be immoral if it ignored the necessity of coining the formal concept. It would also be contradictory given the need for the personal perspective on morality. The personal perspective only makes sense if the 'I' perspective is to be taken seriously. Overdemandingness destroys the personal perspective. By definition, it depicts the situation in which moral agents have become the plaything of uncontrollable events. (Please note that even a radical utilitarian like Singer (1972) allows for the formal concept. He insists that at some point, the moral agent may take into account their concern for self. In the end, Singer is not a radical altruist.) ${ }^{2}$ In order to determine when and how an agent is overdemanded in real life, it is necessary to draw up concrete, empirically verifiable criteria. In doing so, the concept gets a material content. The 'overdemandingness argument' refuting bystander status in commercial life states that any set of material criteria will imply formal overdemandingness, in a world of scarcity and many oMBS. That is why all duties that lead to this status must be eliminated from the set of duties, relevant for commercial agents. We aim to show that liberalist thinking can reconcile the individual's right to an ordinary life and bystander status, even in today's world with its many oMBS.

\section{The Duty of Beneficence and Its Structure}

The most important duties of the bystander are beneficence and rescue. In this section, we focus on the duty of beneficence. We intend to show that the overdemandingness argument does not make sense if the bystander duties in relation to oMBS are grounded on the duty of beneficence. Within liberalist thought the duty is encased within (self-)restricting mechanisms foreclosing the possibility.

\footnotetext{
2 Please note that Singer (1972) only criticizes the liberalist position in terms of the material criteria it draws up to determine overdemandingness. Many will argue that his radical position on the material criteria place him at the margin of the liberalist position-or even beyond that point.
}

According to Frankena (1963/1973, p. 45), the duty of beneficence is the duty to 'do good and prevent harm.' Kant (1797/1996, vol. VI, p. 452) completes this by stating that beneficence is not just wishing well. It is 'active practical benevolence, making the well-being and the happiness of others one's end.'

An initial step in the process of making beneficence compatible with the right to pursue an ordinary life, is the liberalist idea that the duty must be formulated as a nonmaximizing principle: it is (only) wrong for a moral agent to live their life without ever helping others. However, in a world in which MBS are all around us, that does not sufficiently protect the right to an ordinary life. In the liberalist tradition, the duty of beneficence is therefore given a special structure foreclosing the possibility of overdemandingness ever arising. The idea that the duty of beneficence must have a special structure if it is to be compatible with a morality that also acknowledges a moral agent's right or duty to pursue their own ends, was worked out in a centuries' long (European) tradition of moral thinking, starting in Early Modern thought or even before that time (Schneewind 1998). Here, we follow Kant's version of this old European tradition, as the Kantian tradition has kept on to this quite well (Kant 1785/2002, 1797/ 1996; see also Hill 1971, 2002; Herman 1998; Rawls and Herman 2000; Wood 1999) ${ }^{3}$

In the Kantian taxonomy of duties, some are conceptualized as directly related to (the omission of) action. Typical duties like 'do not steal' and 'do not murder' do indeed have this structure. According to Kant this is meaningful, because morality is - at least in part-owed to others and meant to protect their freedom. In so far as morality is owed to others, morality directly concerns omitting or performing certain actions. Kant refers to duties having this structure as perfect duties (Kant 1785, IV: 421).

However, as many others in the European tradition, Kant argues that our duties to others are not exhausted by the protection of their freedom. Kant grounds this idea on the principle of autonomy but that is not important here. Important is that, he had to find a conceptual way of making it possible to think that we may have duties as bystander, without these duties immediately overdemanding the moral agent, given that there is so much bad in the

\footnotetext{
${ }^{3}$ Schneewind (1998) points out that Kant uses familiar terms and familiar distinctions but sometimes changes the use of wellestablished terms in his own idiosyncratic ways. What is more, students of the Kantian moral taxonomy have noted that many of Kant's terms are underdetermined (Rosen 1993, p. 99). As a consequence, many contemporary Kantians use the names of the many distinctions in various ways. However, if we concentrate on the meaning and the function of the distinctions, the consensus is much greater. In this spirit, we have concentrated our analysis on meaning and function, while acknowledging that some people use different names to refer these same meanings.
} 
world. Following philosophers preceding him, Kant finds a solution in the idea of duties that primarily relate to the (internal) quality of the moral agent's decision-making process. In particular cases, these duties do not demand anything of the moral agent in terms of concrete, externally visible actions. They only require them to consider the quality of their decision-making process. Kant refers to this kind of duty as 'imperfect duty' (Hill 2002; See also Herman 1998, p. 169). An imperfect duty is a principle that the agent must necessarily acknowledge as relevant in their decision-making process (Kant 1797/1996, vol. VI, pp. 382-384 and p. 393). 'Beneficence' is a core example of an imperfect duty.

The old European idea that duties can either be perfect or imperfect is another important restriction on the way in which the duty may imply concrete actions and thus checks overdemandingness. If overdemandingness is ever a problem, it must be in relation to perfect duties as they directly relate to actions. Imperfect duties are duties in so far as we are obliged to take a principle (i.e., 'helping others') into account in our decision-making process. Unlike perfect duties, imperfect duties do not necessarily oblige us to prioritize the principle in our decision-making process whenever it is judged that the duty applies. In Kantian words: 'the ends of others' need not always be the 'determining maxim of action' (Kant 1797/1996, vol. VI, p. 393; See Hill 2002, p. 207). In each and every decisionmaking process, there will be other relevant principles to consider, including relevant self-regarding principles. Taking the principle of beneficence into account may never be overlooked (that mental, reflective activity is a duty) but the principle does not necessarily trump all other relevant considerations in specific instances and thus determines concrete actions.

The idea that beneficence is an imperfect duty implies that in no specific case other agents do have a title to accuse an agent of wrongdoing as regards the duty of beneficence. In the liberalist tradition, this is actually true for two reasons. In a specific situation, it is simply never wrong-after consideration - not to make the principle of beneficence the determining principle of action. It is only wrong to refuse to take into account the principle as such. It is wrong to say: 'I will live my life upholding the principle that I will never make other agents' happiness my concern.' The other reason is that the judgment about prioritizing the duty of beneficence is always to be made by the agent themself. This follows from that fact that the duty of beneficence is not owed to others. Hence, others never have a title to claim that you were wrong.

The conceptualization of beneficence as an imperfect duty implies that moral agents always have three options while making a concrete judgment when confronted with a MBS. Given that the agent is a rational moral agent, they can (1) evaluate the situation as one in which there are good and reasonable arguments to make the duty of beneficence the 'determining maxim of action' and choose an appropriate action accordingly. They can also (2) evaluate the situation as one in which there are good and reasonable arguments not to make the duty of beneficence the 'determining maxim of action' and (3) evaluate the situation as one in which there are good and reasonable arguments to make the duty of beneficence the 'determining principle' yet still not act on these reasons. For both option (1) and (2) it goes that not each and every agent will come to the same exact conclusion, given the fact of moral pluralism. For all these three options it holds that whatever the agent decides in a particular case, it is never wrong. What is more, other agents must accept that it is the agent who has the authority to make the decision.

It is interesting to note that this account of beneficence as an imperfect duty is in line with the intuitions of common morality. An example may illustrate this. When somebody walks past a beggar they can decide to do something (e.g., give money) or to do nothing. When the agent prioritizes the duty of beneficence, they will do something to help the beggar. When they do not give any money, we do not typically condemn the agent as having acted morally wrong. Common morality rejects the idea that we must act on the duty of beneficence all the time. Even in a case in which many people would think it appropriate to give some money, there may be circumstances only known to the agent that may make the judgment not to give any money, perfectly reasonable. Besides, even if it were completely unreasonable not to give some money, the decision lies with the agent and with nobody else. Even in that case, we cannot say that the agent did anything wrong in that specific situation.

Proponents of the overdemandingness argument may claim that there are still too few restrictions on the duty. The danger of overdemandingness is still not fully contained. The imperfect structure may help against the idea that an agent must always acknowledge a duty; it does not help to counter the problem of overdemandingness once a dutiful agent has established that the duty must be acknowledged. Since today's world is ridden by oMBS, moral agents may still have to conclude that the duty applies quite often. Hence, the danger of overdemandingness still looms.

Kant's taxonomy of (kinds of) duties can also rebut this criticism by adding another distinction to the taxonomy of duties; a distinction not overlapping with the distinction between perfect and imperfect duties. Kant distinguishes between duties in terms of the level of discretion agents acquire when it comes to executing a moral duty, once it has been established that it ought to be prioritized as determining maxim of action. Some duties leave little 
leeway to the moral subject in how to make personal decisions about executing them. The duty not to steal is an example (albeit a duty that is clear on what the agent cannot do). Other duties leave much more leeway in terms of 'when, what and how.' Beneficence is a core example. When confronted with a poor person, the moral agent may give him some money or a lot of money. Moral agents are also at liberty to decide to comfort him with a meal or make a call to some welfare organization etc. Kant articulates this distinction in terms of discretion, by distinguishing 'duties of narrow obligation' and 'duties of wider obligation' (Kant 1797/1996, vol. VI, pp. 390-393). This distinction pertains to the level of discretion that agents have in executing a duty in terms of when, what and how. It is best looked upon as a scale with, at one pole, duties that do not leave any discretion in terms of personally deciding the 'when, what and how' (narrow obligation) and at the other pole, duties that leave much leeway in these terms (wider obligation). The duty of beneficence is a duty of wider obligation. Hence, even when it is decided that the duty must be prioritized, the overdemandingness problem will not come about. Moral agents have personal discretion in deciding on how to execute the duty, even if it is clear that it ought to apply.

\section{The Duty of Rescue}

We have shown that the status of bystander can never imply overdemandingness, if the ground of duty is beneficence. Beneficence contains mechanisms restricting the consequences of the obligation in terms of concrete actions agents must perform. Nevertheless, some authors think that the best ground for the bystander status in relation to oMBS must be the duty of rescue, in particular when we worry about overdemandingness (Dunfee 2006; See also Scanlon 1998; Soule et al. 2009). In this section, we will briefly characterize the duty of rescue as a ground for bystander duties. In the next section, we intend to show that the duty of rescue is not well suited to serve as ground for the bystander status if we focus on oMBS.

The duty of rescue also is a bystander duty. Some of its characteristics clearly expose it to the danger of leading to overdemandingness in relation to oMBS. First, when an agent must judge that the duty of rescue applies, help is required. Acknowledgement in relation to a situation implies action. The bystander to a person drowning in a pool must help. Refraining from all action is wrong in such a case. This means that the duty of rescue is a perfect duty; actually one of the very few perfect duties that are not structured as a duty of omission (i.e., 'not do.'). This does not mean that everybody has to do the same thing. The duty is not strictly narrow. When it comes to executing the duty there is some discretion. That is necessary, if only because of practical circumstances. When you cannot swim, you better not dive into the water to rescue a person. In these circumstances, you had better alert somebody else. Second, in case of rescue, the victim is at an immediate loss; not helping will have grave consequences for that person. Herman (1998) articulates this by saying that rescue becomes operative when an agents 'true needs' are endangered.

However, some of the characteristics of the duty of rescue clearly put restrictions on the duty when we have to acknowledge it in practice and must act on it. These characteristics diminish the danger of overdemandingness. First, in the case of the duty of rescue, it is much clearer when one stops being a bystander. When the drowning person is out of the water with a blanket on and the proper authorities have arrived, the moral agent can go about their own business again. Second, rescue is typically considered to be restricted by the fact that the rescuer only has to make a small sacrifice (Scanlon 1998). This is why rescuing a person from a burning house is not dictated by the duty of rescue.

\section{The Duty of Rescue and oMBS}

In this section, we intend to show that if bystander duties in relation to oMBS are grounded on the duty of rescue, the problem of overdemandingness can indeed not be foreclosed. The duty of rescue has some restricting mechanisms but these fail to avoid the problem. The restrictive mechanisms are washed away by the enormity of the problem facing the moral agent. We follow Tom Dunfee's discussion of the subject. The late Dunfee (2006) has tried to ground the bystander status, in relation to oMBS on the duty of rescue. Dunfee saw all to well that a full fledged 'right to moral indifference' as propagated by MMM ruins the personal perspective. If such a right is given to commercial agents, they can claim a right to be indifferent to the worst of circumstances and still consider themselves to be moral agents.

Yet, Dunfee was also well aware of the overdemandingness problem. In other publications, he is one of the authors that insists on the idea of MMM (Donaldson and Dunfee 1999). This must be the reason why Dunfee spends much time constructing his argument in such a way that the charge can be averted. Because of all these counteracting strategies, his argument for bystander status takes a form of something that only applies 'in rare cases' (see also Soule et al. 2009 for a similar kind of argument). We intend to demonstrate that he failed, still.

Dunfee argued that when a 'devastating catastrophe' takes place, companies with 'unique competencies' have a 
'mandatory moral obligation' (2006, p. 187) to help. Dunfee thinks that the AIDS epidemic is such a unique case, especially when considering pharmaceutical companies as bystanders. According to Dunfee, rescue is the proper ground exactly because this duty has to be acknowledged in the worst of circumstances: when people's true needs are at stake. Dunfee constructs various arguments to "defuse" the charge of overdemandingness that he knows will be raised against his argument. As a first step, Dunfee emphasizes that the (true) need must be extremely great (2006, p. 187). We do not think that this is a valid reason to limit the duty of rescue. When a person's true needs are violated, their circumstances are already exceptional. It is non-sensical to create a category of 'extra' true needs. The requirement to help also cannot be made conditional upon a quantitative criterion. As regards true need, quantity does not count.

Another strategy used by Dunfee is to argue that the market agent must be extremely well placed: they must be 'uniquely positioned' in terms of the relation to the oMBS. Again, why does one only become a bystander if one is uniquely positioned? The status of bystander is already conditioned by the requirement that a set of symbolically relevant criteria must apply. Morality is eroded by insisting on more unique features. What is more, Dunfee seems to suggest that moral agents are in a strange kind of competition, determining who is 'most uniquely positioned.' That goes against the personal perspective presupposed by the idea of a bystander. Each person must determine for themselves whether they are a bystander, in relation to the case at hand. (This does not mean that bystanders cannot cooperate. It only means that the acknowledgement of the status is a personal affair that must be undertaken irrespective of the considerations of others.) What is more, Dunfee's own core example is the relation between pharmaceutical companies and the AIDS problem. How truly exceptional is that relation? It is about a company having a resource that some people truly need. In a world of scarcity every company must have at least a few of these relationships.

Dunfee argued that the relation must also be unique in terms of the resources the bystander controls: 'the core competency of the firm must enable it to mitigate or alleviate the source or cause of the catastrophe," (Dunfee 2006, p. 188). Again, we must question whether this attempt at restriction is valid. Dunfee again pushed for more stringent criteria and suggested that there is strange kind of competition going on between agents, now in terms of resources. That is a misconception. Dunfee's own examples make this clear. In developing his case for rescue, Dunfee worked out a fictional case about a doctor specialized in allergic reactions who visits a children's farm in his free time. This doctor gets accidentally confronted with a bunch of children who have been stung by bees. A few of them develop life-threatening allergic reactions. In Dunfee's scenario, this doctor happens to have a bag full of medicines on them. Dunfee argued that in this particular case, the doctor has a mandatory requirement to help. He then argued that since the position of pharmaceutical companies vis-a-vis AIDS is comparable to the position of the doctor, they also have a mandatory requirement to help, grounded in the duty of rescue. Now, we are not disputing that in these exceptional circumstances the doctor has a mandatory requirement to help. Yet, we are disputing that all the other people present in the children's farm are not also mandatorily obliged. At least some of them may also be well placed, on different but as relevant criteria. Common morality would already find the fact that someone is present at the scene to be symbolically relevant. Because of that presence you should at least check out whether you could be of some assistance (make phone calls to parents, calming the children etc.).

As a last strategy suggested by Dunfee is that moral agents must accept being submitted to a small voluntary (pseudo) 'tax' based on a percentage of yearly profits. The idea of such a voluntary tax seems to have been made with the overdemandingness problem in mind: a small percentage of profits can never be overdemanding. The problem with this solution is that the idea of an obligatory annual gift is out of touch with the idea of being a bystander on account of the duty of rescue. An agent who has to acknowledge the duty of rescue asks themselves: what is there to do here and now? It is also out of touch with the personal perspective on morality presupposed by the idea of a bystander. Given the personal perspective, it is important to demonstrate the relation with direct, required action that has to be performed, here and now. The tax has nothing of that kind. It is more like an anonymous and pseudo institutional solution broken free from the personal perspective. One of the ways in which this shows is that it is hard to argue why only 'uniquely positioned' bystanders must pay this money. If it all comes down to paying money, there is no rational for the requirement that the bystander must be uniquely positioned.

The conclusion of this section must be that Dunfee cannot avert the charge of overdemandingness. When bystander status is grounded in the duty of rescue, the problem of overdemandingness will arise. It should be pointed out that the problem of most reasons is not that they are impracticable. Some strategies fail because Dunfee's attempt to define a 'rare space' for the duty of rescue does not make sense. The delimitation between cases in which agent would and would not become bystanders, would become arbitrary while only inspired by a need to define a rare space of application. An example is the attempt to reduce the idea of 'true need' to 'extremely great 
need.' Other strategies fail because they are incompatible with the nature of the duty of rescue and the personal perspective on morality in which the duty makes sense. An example is the idea of a voluntary 'tax.'

\section{Subjective Urgency}

The goal of this paper is to demonstrate that MMM is wrong when it argues that because of the problem of overdemandingness, commercial agents must be granted a right never to assume the status of bystander. Up to now, we have shown that this argument fails if bystander status is grounded in the duty of beneficence. We have also shown that the charge makes sense if the duty of rescue is considered the ground of the status. One way to save liberalist thought would be simply to say that we should only ground bystander status in relation to oMBS on the duty of beneficence. But this would be a disappointing way of going about. It seems that the duty of rescue is ousted as ground on the basis of an arbitrary reason. In this section, we therefore aim to show that there are structural reasons foreclosing the possibility to ground bystander status in relation to oMBS on the duty of rescue. An important condition for the possibility of acknowledging the duty has not been fulfilled: subjective urgency.

Agents only have to acknowledge a duty in practice when particular conditions are fulfilled. A condition relevant for the duty of rescue is for example 'true need' on the side of the victim. We argue that within the liberalist position, the duty of rescue only has to be acknowledged if the condition 'subjective urgency' is fulfilled. The relevance and meaning of this condition is often overlooked. As a consequence of this, proponents of MMM argue that liberalist thinking contains a problem that must be fixed by granting commercial agents a right never to assume the status of bystander. In reality, the duty of rescue does not at all apply to situations in which a moral agent is confronted with an oMBS.

Subjective urgency focusses on the position of the acting agent; the agent who has to acknowledge the duty of rescue. Subjective urgency is the realization on the part of the moral agent that they are the one who must act now. 'If $I$ do not now take single, definitive steps, the moral badness will come into full force.' The drowning person will actually drown, and the lethally stung children will actually die. In all the examples, we have used (Dunfee's included) subjective urgency has always implicitly been taken into account. Exactly because of subjective urgency, the doctor and the good swimmer are called upon by the duty of rescue. They can do something now.

As we see it, moral agents are not called upon as bystanders by the duty of rescue in relation to oMBS, exactly because the subjective urgency condition is not fulfilled. The reason is somewhat paradoxical. An oMBS defines a relation between the agent and a MBS. By definition, oMBS overwhelm the moral agent. There is not really one thing the agent could do-here and now-that would make a difference in terms of solving the problem. Everything the agent could do, here and now, is meaningless in terms of solving the problem. Here and now, the agent cannot change much about the oMBS. The problem is so big, the agent can only understand it through instantiations. Exactly because of that, the subjective urgency needed to make the duty of rescue operation vanishes.

Obviously, our argument must not be interpreted as implying that when a moral agent is confronted with a situation that they have good reason to interpret as the instantiation of an oMBS, they require a right to do nothing as that is meaningless. That is exactly what the protagonists of MMM try to argue. The conclusion must be that if moral agents have reason to interpret a situation as a confrontation with an oMBS the duty of rescue does not apply but they must consider themselves bystanders on account of the duty of beneficence. (What that means in terms of concrete actions is beyond the scope of this paper but it can vary. If the duty of beneficence calls upon the agent to act, some will focus on the real life case beyond the instantiation and do something for these concrete victims. Others will take the instantiation as a reason to put energy in longterm improvements, like better law giving. All that belongs to the discretion of the moral agent).

As yet, we have only explained the meaning of subjective urgency. We have not clarified why that condition is crucial to liberalist moral thought. Liberalist thinking conceives of human beings as moral creatures; in the sense that they are and must remain (i.e., improve as) moral creatures (Kant 1788/1903; Herman 2007). As a consequence, the personal perspective on morality cannot be given up. It may even be its core. If the personal perspective is ever relevant, it must be in situations in which the agent is confronted with the true needs of other moral agents. Hence, liberalist thinking can never give up bystander duties. That would not only ruin the perspective; it would ruin morality as such. Hence, from a liberalist perspective (and common morality for that matter), it makes sense to assume that moral agents must have a duty of rescue and to conceptualize this duty as perfect and narrow. At the same time, it also makes sense to put strong conditions on this crucial duty; otherwise it may inflate quickly in a world in which there is so much bad. 'Subjective urgency' is a condition that makes the duty meaningful yet also limits it in a proper way.

Second, from the personal perspective, the meaning of morality can never be 'solving moral problems' or 'doing away with the MBS one is confronted with.' In a world of 
scarcity and all manner of other kinds of imperfections, individual moral agents will probably always have to swim in an ocean of MBS (see Fried 1978). Moral agents must do their part to make institutions work but from the personal perspective trying to relate in the right way to MBS can only make sense if saving or upholding the moral agent's own status as moral agent (is part of) what it is all about. This is articulated in the idea of 'subjective urgency.' It is not only the other moral agent's true need that hangs in the ballot; it is (also) the moral agency of the bystander themselves.

\section{Beneficence as a Meaningful Duty}

Some may argue that we have indeed shown that beneficence can be the ground of duty in relation to oMBS, but is that duty to be taken seriously? If beneficence is 'only' an imperfect duty and only of wider obligation on top of that, does it really make a difference, especially in relation to business agents working on the market? How seriously can we take a duty that does not lead to wrongdoing in concrete situations and that never gives others a title to accuse the agent of anything? First thing to say is that even if beneficence were a 'weak' duty, it would still be of enormous value in opposing the belief that morality allows us to behave in a 'strictly business' way. Those defending unrestrained forms of capitalism sometimes argue thatwithin minimum moral limits-business people are allowed to be concerned only about the maximization of profit in business. If beneficence is a duty, we can accuse agents making this argument of committing the only possible wrong in relation to the duty of beneficence: to live by the principle that one will (never) take the duty of beneficence into account in one's decision-making process. The 'strictly business view' denies that morality has a personal dimension and is an immoral view, exactly because of that.

Second, there is a fundamental difference between insisting that a moral agent has a right to decide on an issue and saying that the agent is allowed to make any arbitrary decision they like. Each agent has the right to make their own decision but decisions are only right when they fulfill certain criteria, i.e., are reasonable. If beneficence is to be a duty, it must be. (.)... a serious, major, continually relevant, life shaping end (Hill 2002, p. 206). This undercuts the worry expressed by Dunfee (2006) and others that if beneficence is merely an imperfect duty, commercial agents have a moral right never to prioritize the duty or have a moral right to argue that they have fulfilled the duty of beneficence vis-a-vis the AIDS crisis by making a donation to a local opera house. As moral agents, they cannot do this.

Third, the fact that other agents do not have a title to accuse the agent of wrongdoing in a particular case does not mean that other agents must remain completely passive. As free moral agents they are morally allowed to change their behavior toward another agent. Other agents cannot punish an agent on account of the latter's way of dealing with the duty of beneficence but they can reconsider their relationship with the agent because of their own view of life. In this indirect way, the non-beneficent agent may experience bad consequences of their decisions. Moral agents may not be allowed to say to a miser that they did something wrong and therefore punish them. Still, they are not required to remain friends with them either. By the same token: even if a moral agent cannot accuse the nonbeneficent market agent of doing anything wrong, they may decide to do their shopping elsewhere. The fact that moral agents are not allowed to punish her does not mean that they cannot freely decide to switch to another business more in tune with their sense of morality.

Two comments rebutting the idea that beneficence is a 'weak' duty, have a more specific Kantian touch to them but it may be interesting to spell them out. They show how Kantian thought can be relevant in bolstering the importance of beneficence as an imperfect duty. Kantians oppose the tendency within modern society in general, and business ethics in particular, to reduce morality to a mechanism to be used for social coordination and control (Wood 2002). Because of this reduction, the meaning of morality comes close to legality-it only has a weaker means of securing the compliance of moral agents. From a Kantian point of view this misconceives morality. Ultimately, morality concerns the process of becoming "one's own master" (Kant 1788/1903, vol. V, p. 33). It is about willing to be, and willing to become, an agent who takes into account certain (self-constraining) principles in their decision-making process. Looking at beneficence from this perspective beneficence is a core duty, exactly because it is not supported by non-moral means of enforcement. In so far as commercial agents will to be moral agents, they cannot ignore this core duty.

Our next comment follows up on this. Kant (1797/1996, vol. VI, p. 390) distinguishes between two kinds of moral failing: that is, two ways in which a duty can be violated. In so far as morality concerns violating the freedom of another moral agent, violating a duty means acting morally wrong. In so far as morality concerns the process of becoming 'autonomous,' violating a duty is 'merely nonvirtuous.' When an agent wrongs others, the others gain a title to blame and punish them. Merely non-virtuous actions never give others that status. Others must regard merely non-virtuous behavior as permissible in the broadest sense of that word. This state of affairs seems to make 'merely non-virtuous actions' a lesser kind of moral failing. However, in so far as morality ultimately concerns attaining autonomy, it is the worst kind of moral failing. Again, 
in so far as an agent will to be a moral agent, they must take this duty seriously.

\section{Conclusion}

It has long been the common view within business ethics that the morality of the market is a limited morality that excludes all bystander duties. The idea of bystander duties only makes sense from the personal perspective on morality. In this paper, we investigated the argument that bystander duties must be excluded because they imply overdemandingness. This argument seems to make a lot of sense in relation to oMBS and thus threatens the liberalist position that tries to unite the moral agent's right to an ordinary life with bystander duties.

It is demonstrated in the paper that the overdemandingness argument only makes sense if it is believed that commercial agents who are confronted with an oMBS, are obliged as bystanders by the duty of rescue. The argument crumbles if the duty of beneficence is taken as the ground of duty. Due to its structure, the duty of beneficence cannot become overdemanding. Still, beneficence is a meaningful and important duty. We have also shown that the duty of rescue only has to be acknowledged if the condition of subjective urgency is fulfilled. That is not the case when a moral agent is confronted with an oMBS. Hence, the charge of overdemandingness does not threaten the liberalist position. It also follows that the argument put forward by protagonists of MMM fails. There is no moral right to refute the status of bystander in relation to oMBS.

Open Access This article is distributed under the terms of the Creative Commons Attribution 4.0 International License (http://crea tivecommons.org/licenses/by/4.0/), which permits unrestricted use, distribution, and reproduction in any medium, provided you give appropriate credit to the original author(s) and the source, provide a link to the Creative Commons license, and indicate if changes were made.

\section{References}

Baumol, W. J. (1975). Business responsibility and economic behavior. In M. Anshen (Ed.), Managing the socially responsible corporation (pp. 59-74). New York: MacMillan.

Bosma, M. 2012. The duty to assist the poor and the extent of its demands. A Kantian approach. Tilburg: Privately Published.

Donaldson, T. (1989). The ethics of international business. New York: Oxford University Press.

Donaldson, T., \& Dunfee, T. W. (1999). Ties that bind. A social contracts approach to business ethics. Boston: Harvard University Press.

Dunfee, T. (2006). Do firms with unique competencies for rescuing victims of human catastrophes have special obligations? Corporate responsibility and the aids catastrophe in sub-Saharan Africa. Business Ethics Quarterly, 16(2), 185-210.
Elfstrom, G. (1991). Moral issues and multinational corporations. London: MacMillan.

Frankena, W. K. (1963/1973) Ethics (2nd edn). Englewood Cliffs: Prentice-Hall.

Fried, C. (1978). Right and wrong. Cambridge: Harvard University Press.

Goodin, R. E. (2009). Demandingness as a virtue. The Journal of Ethics., 13(1), 1-13.

Habermas, J. 1981. The theory of communicative action: Lifeworld and system. (Trans. T. McCarthy). Cambridge: Polity Press.

Herman, B. (1998). The practice of moral judgment. Cambridge, MA: Harvard University Press.

Herman, B. (2007). Moral literacy. Cambridge: Harvard University Press.

Hill, T. E. (2002). Human welfare and moral worth: Kantian perspectives. New York: Oxford University Press.

Hill, T. E. (2012). Moral responsibilities of bystanders. Virtue, rules and justice. Kantian aspirations (pp. 343-357). Oxford: Oxford University Press.

Hill, T. E. Jr., (1971). Kant on Imperfect Duty and Supererogation. Kant Studien LXXII 55-76.

Homann, K. (1994). Marktwirtschaft und Unternehmensethik. In S. Blasche, W. Köhler, \& P. Rohs (Eds.), Markt und Moral. Die Diskussion um die Unternehmensethik (pp. 109-130). Bern: Haupt.

Homann, K. (2008). Das Ethische Programm der Marktwirtschaft. Magdeburg: Norbertus-Verlag.

Hsieh, N. (2004). The obligations of transnational corporations: Rawlsian justice and the duty of assistance. Business Ethics Quarterly, 14(4), 643-661.

Kamm, F. M. (2000). Does distance matter morally to the duty to rescue? Law and Philosophy, 19, 655-681.

Kant, I. (1785/2002). Groundwork for the metaphysic of morals. In T. Hill and trans. A. Zweig. Oxford: Oxford University Press.

Kant I. (1788/1903). Kritik der praktischen Vernunft. In: I. Kant (Ed.), Kant's Werke Bd V (pp. 1-202). Berlin: Walter de Gruyter.

Kant, I. (1797/1996). Metaphysics of morals. Trans. Mary Gregor. Cambridge: Cambridge University Press.

Luhmann, N. (1988). Die Wirtschaft der Gesellschaft. Frankfurt am Main: Suhrkamp.

Miller, R. (2004). Beneficence, duty and distance. Philosophy \& Public Affairs, 32(4), 357-383.

Nozick, R. (1975). Anarchy, state, and utopia. Oxford: Basil Blackwell.

Pogge, T. (2002). World poverty and human rights: Cosmopolitan responsibilities and reforms. Cambridge: Polity Press.

Radzik, L. (forthcoming). Moral bystanders: On the social enforcement of morality.

Rawls, J. (1971). A Theory of Justice. Oxford: Oxford University Press.

Rawls, J. \& Herman, B. (2000). Lectures on the history of moral philosophy. Cambridge: Harvard University Press.

Rosen, A. D. (1993). Kant's theory of justice. Ithaca: Cornell University Press.

Scanlon, T. M. (1998). What we owe to each other. Cambridge: Harvard University Press.

Schmidtz, M. (2000). Islands in a sea of obligation. Limits to the duty of rescue. Law and Philosophy, 19(6), 683-705.

Schneewind, J. B. (1998). The Invention of autonomy. Cambridge: Cambridge University Press.

Singer, P. (1972). Famine, affluence and morality. Philosophy \& Public Affairs, 1, 229-243.

Soule, E., Hedahl, M., \& Dienhart, J. (2009). Principles of managerial moral responsibility. Business Ethics Quarterly, 19(4), 529-552.

United Nations, Human Rights Council. (2008). 8th session, item 3) Report of the Special Representative of the Secretary General on 
the Issue of Human Rights and Transnational Corporations and other business enterprises. John Ruggie: Promotion and Protection of all Human Rights, Civil, Political, Economic, Social and Cultural Rights.

Van den Hoven, M. (2006). A claim for reasonable morality. Commonsense morality in the debate on the limits of morality. Utrecht: Zeno.

Weber, M. (1921/1972). Wirtschaft und Gesellschaft. Grundriss der Verstehenden Sociologie. Tübingen: J.C.B. Mohr/Paul Siebeck.
Wood, A. (1999). Kant's ethical thought. Cambridge: Cambridge University Press.

Wood, A. (2002). The final form of Kant's practical philosophy. In M. Timmons (Ed.), Kant's metaphysics of morals. Interpretative essays (pp. 1-21). Oxford: Oxford University Press. 